\title{
DANÇANDO O PESAR DO MUNDO
}

\author{
Patrícia Spindler e Tania Mara Galli Fonseca \\ Universidade Federal do Rio Grande do Sul, Porto Alegre, Brasil
}

\begin{abstract}
RESUMO: Este artigo objetiva pensar as formas mais recentes de viver no mundo, tomando os sujeitos como efeitos de múltiplos desdobramentos produzidos em torno da experiência do viver. Para isso, utiliza a dança contemporânea como mediadora, relacionando-a com certos modos de viver no contemporâneo.
\end{abstract}

É por essa esteira que o leitor é convidado a traçar um caminho por algumas vias que permeiam o plano no qual estamos inseridos, o contemporâneo. No decorrer dessa viagem, encontramos o dançar. Esse movimento se insere na trajetória da dança contemporânea, permitindo-nos deparar com a possibilidade de fazer uso dessa experiência como auxílio para continuar pensando o contemporâneo como ponto-chave da problematização.

PALAVRAS-CHAVE: corpo; dança; contemporaneidade.

\section{DANCING THE SORROW OF THE WORLD}

ABSTRACT: This article aims at thinking the most recent ways of living in the world, considering the subjects as effects of multiple fractions produced around the living experience. For that, it uses the contemporary dance as an intermediary, relating it to certain ways of living in the contemporaneity.

Through this course, we invite the reader to trace a path through some ways that permeate the plan in which we are inserted, the contemporaneity. As this trip goes on, we find the dance. This move is inserted in the trajectory of contemporary dance, allowing us to face the possibility of using this experience as an aid to keep thinking the contemporaneity as the key point of the problem.

KEY WORDS: body, dance, contemporaneity.

Para pensar nossas mais recentes formas de viver o mundo, precisamos visibilizar o que nos compõe, o que está ao nosso redor, percebendo-nos uma formaefeito das dobraduras que compõem nosso feitio. O pensador Ítalo Calvino (1990) nos adverte que estamos correndo o perigo de perder a capacidade de pensar por imagens, ou seja, de dar visibilidade aos nossos pensamentos, uma vez que estamos sobrecarregados de imagens clichês e em nosso pensamento predomina o discursivo intencional, impedindo novas estilísticas e novas fabulações.

Gostaríamos de iniciar através da problematização do que chamamos de contemporâneo. Este se refere a um tempo que não é somente um aqui e agora, tampouco um determinado período histórico. Diz respeito a um modo de habitar o mundo nas suas mais diversas composiçõos espaço-temporais, onde se criam ontologias e epistemes que abrem o leque de experiências possíveis.

Pesar do Mundo

Música de José Miguel Wisnik e Paulo Neves pesar de tudo

pesar de peso

pesar do mundo

sobre si mesmo

pesar de nuvem

pesar de chumbo

pesar de pluma

pesar do mundo

desponta estrela

no vão imenso

por ti suspenso

à tua espera

tudo se afronta 
pedra com pedra

a própria onda

quando se quebra

a melodia

onde me leva

onde alivia

onde me pesa?

tudo se agita

durante a queda

o que sustenta

a nossa Terra?

e nesse quando

somente um ritmo

peso e balanço

um som legítimo

canção sem medo

de você para mim

ó meu segredo

te rezo assim:

desde o princípio

ao ponto cego

eu arremesso

um eco sem fim.

Uma das experiências contemporâneas é dar conta do "pesar do mundo sobre si mesmo" que os compositores ressaltam na letra da música transcrita acima. Algo neste tempo pesa e gera, com isto, padecimentos. $\mathrm{O}$ que se pode perceber é que, para ser leve no contemporâneo, é preciso tolerar um certo peso. Importância que não é pouca quando se fala em tempos de múltiplas variedades dos modos de viver, de consumir, de controlar.

O controle do peso corporal objetivando o leve é uma obsessão contemporânea sem precedentes. Ao mesmo tempo em que muitas adolescentes morrem pelo peso da magreza ordenada pela boa forma exigida estetica- mente, o aumento de peso ameaça a aproximação da obesidade de maneira cada vez mais certeira.

A leveza subjetiva do viver, como aponta a música, está inscrita no paradoxo do peso do chumbo e da pluma, da nuvem e do mundo. O etéreo e o concreto, contrapontos que denotam a inconsistência da leveza e a durabilidade do sólido. Peso que se encontra em ambas as pontas deste nó, "ponto cego... um eco sem fim", acelerando o tempo e podendo nos impedir, ou dificultar muito, a possibilidade de sermos mais "light". Não é à toa que as prateleiras dos supermercados estão repletas de produtos desse tipo para serem ingeridos. Estilo de vida diet-light, algo que pesa numa proporção muito maior e veloz que a produção da leveza, pois esta se produz de outras formas, por outros caminhos que balançam num ritmo que ora quebra e queda, ora suspende e sustenta.

Seguindo com Calvino (1990), entre os "valores caros" que anuncia para o nosso novo milênio, a leveza é um a que ele atribui estimada importância. Para o literato, ela é necessária para suportar o insustentável peso do viver. Há uma necessidade de anular o peso material da corporeidade para se juntar com a velocidade e prometer acesso a um nível que modifica a realidade como possibilidade de felicidade. Quanto mais leve, mais veloz. Quanto mais veloz, mais alternativas do leque podem ser percorridas. Ou seja, todas essas perspectivas presentes no social pesam no corpo, pois este também está inserido e, ao mesmo tempo, sendo construído por este conjunto de atravessamentos que compõem este momento histórico.

De outra maneira, o sociólogo Zygmunt Bauman (2001) descreve a passagem do capitalismo pesado para o capitalismo leve marcado pelo fordismo, que era, mais do que tudo, uma engenharia social orientada pela ordem. "O fordismo era a autoconsciência da sociedade moderna em sua fase 'pesada', 'volumosa', ou 'imóvel' e 'enraizada', 'sólida'... O capitalismo pesado era obcecado por volume e tamanho, e, por isso, também por fronteiras, fazendo-as firmes e impenetráveis" (p. 69). A fábrica fordista reduziu as atividades humanas a movimentos simples, rotineiros, predeterminados, para serem seguidos mecanicamente, sem qualquer espontaneidade e iniciativa. A burocracia, o panóptico e o Grande Irmão faziam o controle numa tentativa totalitária de nada deixar passar, principalmente na fronteira entre o dentro e o fora da fábrica.

Conforme Bauman, a modernidade pesada foi a era da conquista territorial; o progresso significava tamanho crescente e expansão espacial. O tempo métrico da rotinização precisava ser amansado para que o espaço também fosse controlado. A solidez da modernidade do hardware encorpou os lugares, tornando-os, simultaneamente, viveiro, fortaleza e prisão.

No entanto, a mudança na história moderna do tempo, da era do hardware para a era do software, traduziu- 
se numa nova irrelevância do espaço, disfarçada de aniquilação do tempo. O software substituiu o hardware na centralidade da cena contemporânea. Da mesma maneira, a instantaneidade descreve a modernidade leve e líquida, como também constatou Bauman. A leveza, a agilidade e a velocidade, portanto, passaram a preponderar no tempo como atributos que levavam ao controle e ao comando das estratégias no processo de globalização da economia na modernização do mundo.

Um mundo que se transformou no Império do Efêmero em suas mais diferentes experiências, conforme Gilles Lipovetsky (1989). Pois, é a

forma moda que se manifesta em toda sua radicalidade na cadência acelerada das mudanças de produtos, na instabilidade e na precariedade das coisas industriais. A lógica econômica realmente varreu todo ideal de permanência, é a regra do efêmero que governa a produção e o consumo dos objetos. Doravante, a temporalidade curta da moda fagocitou o universo da mercadoria, metamorfoseado, desde a Segunda Guerra Mundial, por um processo de renovação e de obsolescência "programada" propício a revigorar sempre mais o consumo (p. 160).

Ou seja, toda essa aceleração criou a sociedade do consumo, que insere o cotidiano na pragmática do comprar, reciclando-o em kits e serviços expressos. Um tempo contraído, em que tudo acontece com uma rapidez que cada vez mais se potencializa, fazendo coexistirem os tempos múltiplos. Percebe-se isso na moda, nos comportamentos, nos objetos, no design do contemporâneo. Ao contrário de querer homogeneizar essa diversidade, pretende-se mostrar o quanto nossos últimos anos foram transformadores tomando um caráter múltiplo, complexo, rápido, e, também, ambíguo, vago, plástico.

Calvino (1990) também pontua a multiplicidade como elemento necessário para pensar o contemporâneo. Para ele, o mundo é um "sistema de sistemas", em que cada sistema particular condiciona os demais e é condicionado por ele. Portanto, uma complexidade intrínseca que não permite achar conclusões, pois vai fazendo seu traçado de maneira a esquivar-se, multiplicando os detalhes ao infinito.

Afina-se com Calvino Lipovetsky (1989), quando pensa a forma moda como o sistema das pequenas diferenças multiplicadas, engendrando universos de produtos microdiferenciados. Portanto, o processo de renovações constantes produz a busca pelo novo, transitoriedades, frivolidades, flexibilidades, efemeridades, instantaneidades que fazem do tempo um click do mouse. Assim também instabilidade, precariedade, vulnerabilidade, insegurança fazem parte do rol das experiências contemporâneas. Nesse contexto, há um pano de fundo chamado liberdade individual, que se tenta alcançar a qualquer preço, pois promete infinitas possibili- dades. Com isso, a agonia da escolha parece ser um dos vilãos do contemporâneo, também porque não há tempo para perder na eleição de alternativas, mas, muitas vezes, acaba-se vivendo exatamente aí, nesse processo da ambivalência da escolha. A vida paradoxal joga os sujeitos de um lado ao outro, num disparate de movimentos.

Fazemos uma tentativa de não confundir essas diferenças multiplicadas em renovações constantes, que os autores que nos auxiliam a enxergar com maior visibilidade o contemporâneo nos prescrevem, com o que Bergson (1964) e Simondon (2003) discorrem sobre a duração do ser e a individuação do vivo. Processos estes que não param de acontecer na ordem da vida. Porém a questão referida por esses autores não será trabalhada nesta ocasião. $\mathrm{O}$ esforço que se está fazendo aqui para tentar pontuar esses processos como diferentes é justamente porque também se entende que estas questões da evolução do vivo se confundem com as experiências contemporâneas, potencializando essas vivências como um disparate de movimentos efêmeros. No entanto, esses são sintomas do nosso tempo, onde o capitalismo cafetina o desejo, decalcando-o, competindo em paralelo com a evolução da vida nua, esta sim criadora.

Vivemos em templos de consumo, com ou sem muros, como shoppings, lojas, nossas próprias casas servindo para comprar pela televisão, telefone, internet, ou circulando por onde passamos num comércio a céu aberto. Uma "cultura de cassino", como disse George Steiner (conforme citado por Bauman, 2001), em que o êxtase dá a ordem, para que a auto-satisfação instantânea seja constante e irrefletida. Porém, tanto a chegada da satisfação quanto sua partida estão fazendo pressão na transitoriedade do tempo.

As pessoas querem o mundo de maneira completa porque buscam a construção da identidade como uma imagem de lógica harmônica e consistente, para não verem "a terrível fluidez logo abaixo do fino envoltório da forma" (Bauman, 2001, p. 97). Isso acaba gerando uma intensa angústia, que leva à experiência de desestabilização constante vivida no contemporâneo. As infinitas possibilidades do suposto "mundo completo" geram movimentos ininterruptos, ora contínuos, ora descontínuos, que fazem da rapidez de incorporar esses processos a chance de inventar um ritmo de sobrevivência.

Busca-se a identidade no imediatismo do tempo, na tentativa de não sentir os colapsos provocados pela experiência contemporânea. Por outro lado, a vida provoca, o tempo inteiro, microcolapsos imanentes ao vivo. Francisco Varela (2003) fala de "microidentidades" que são uma espécie de prontidão-para-ação adequada para cada situação específica vivida. Estas "microidentidades" possuem uma situação correspondente que o autor chama de "micromundos", ambos construídos historicamente. Porém, ele salienta que as maneiras novas de se com- 
portar e as transições entre uma ação "pronta" e outra correspondem a microcolapsos que sofremos constantemente, numa rapidez que parece estar em constante aceleração. Talvez por isto, a vida humana contemporânea tornou fundamental a experiência das grandes velocidades, pois nesse ritmo pode-se tentar fazer com que esses microcolapsos não sejam sentidos e, paradoxalmente, também podem gerar sensações que provoquem e salientem os colapsos ainda mais.

Para o pesquisador Christian Pociello (1995),

a vertigem, a velocidade, o mergulho, a queda, os desequilíbrios de todas as espécies reforçam o "ilinx ${ }^{1 "}$ " esportivo, renovando-o. Eles delimitam um universo lúdico que curiosamente faz das sensações de instabilidade uma fonte de prazer, e das desordens que elas procuram uma espécie de busca paradoxal (p. 118).

Este autor ressalta que o paradigma de todas as dificuldades é a libertação do peso, mesmo que por um instante. Essas sensações são muito ilustradoras do contemporâneo e talvez da passagem à pós-modernidade. Fala-se da fluidez que sustenta o tempo em curto prazo da montagem e desmontagem do mundo, assim como se usa a metáfora do surfar e do dançar para dizer que se vive hoje no capitalismo leve. Essas metáforas são bem escolhidas, de acordo com Bauman (2001), pois sugerem falta de peso, leveza e facilidade de movimentos. Mas o sociólogo ainda afirma,

não há nada de "mole" na dança ou no surfe diários. Dançarinos e surfistas, e especialmente os que vivem na pista do salão de baile lotado ou na costa batida por altas ondas, precisam ser duros, e não moles. E são duros - como poucos de seus predecessores, capazes de ficar parados ou mover-se em trilhas claramente marcadas e bem mantidas, jamais precisaram ser. O capitalismo software não é menos firme e duro que seu ancestral hardware. E líquido não quer dizer mole. Basta pensar no dilúvio, numa inundação ou na ruptura de um dique. (p. 251)

O contemporâneo, portanto, pode ser adjetivado por características como multiplicidade, complexidade, rapidez, ambigüidade, paradoxal, difuso, incerto, caótico, plástico. Não se quer, aqui, fazer um mapeamento dos valores contemporâneos para apreender o bom e o mal, mas pensar alguns desses atributos que são vivenciados nas práticas deste tempo, para além do bem e do mal.

Dar formas ao vivo nestes tempos é uma arte de viver no labirinto ou na corda bamba como equilibrista. As formas, portanto, são breves. E não queremos nos opor a estas brevidades; pelo contrário, é nelas que precisamos operar, desacelerando um pouco para que possamos pensar, inventar, sem sair do fluxo no qual estamos imersos. Pois é neste ponto que nos encontramos, vive- mos e, portanto, é deste lugar que podemos nos apropriar para ocupá-lo ou também mudá-lo.

As mudanças da dança

Intencionamos continuar utilizando o dançar para prosseguir problematizando o contemporâneo. Será através de lentes de cristais que devemos olhar a dança contemporânea: como um prisma que se abre em múltiplas cores. Ou seja, não podemos pensar nem "ler" essa modalidade artística com um bloco homogêneo. Muito pelo contrário, a dança contemporânea foi se fazendo de uma maneira tão múltipla, que as suas formas divergem bastante, podendo dizer que fazem parte de movimentos bem diferentes. Seus criadores e bailarinos foram dando muitas caras à dança que surgiu, de maneira geral, na tentativa de se libertar dos padrões rígidos do balé clássico. Para a pesquisadora de dança Ciane Fernandes (2002), "o início do século XX apresentou uma revolução estética que rompeu a barreira entre as artes em movimentos como o Dada e a Bauhaus, originando a dança moderna como uma rebelião contra o tecnicismo do balé clássico" (p. 36). Foram muitas formas de dançar que surgiram a partir desses rompimentos que foram se fazendo possíveis em função de movimentos maiores que se davam nas artes em geral.

No entanto, a dança moderna, mesmo criada com objetivos contestatórios, na tentativa de sustentar uma arte mais livre, foi se desenvolvendo com cautela ao longo do conservadorismo político e artístico da guerra fria, que, nos anos 40 e 50, se travava também com o balé. Houve, então, uma crescente especialização e aprimoramento técnicos, na medida em que a dança moderna fazia seu processo de criação e institucionalização.

Nos anos 60, novamente os artistas buscaram expandir as fronteiras entre as artes, rebelando-se contra o modernismo, gerando uma multiplicação das correntes da dança pós-moderna. Este movimento da contracultura na década de 60 foi mundial, ocorrendo em parte significativa da juventude, que, conforme a psicanalista Suely Rolnik (2001), fez eclodir "na subjetividade da geração nascida no pós-guerra um incontornável movimento do desejo contra a cultura que se separou da vida, na direção de reconquistar o acesso ao corpo vibrátil como bússola de uma permanente reinvenção da existência" (p. 319). Com relação à dança, isso foi marcante no que diz respeito à evidência que tomaram as diferenças entre o balé e a dança moderna. Para a autora que pesquisa história da dança, Maribel Portinari (1989),

houve de tudo em nome da vanguarda, do melhor ao pior. Estava em cena a contestação. Dançou-se pois para protestar a guerra no Vietnã, contra o racismo, contra o sexismo, contra o establishment. E para celebrar a paz, o amor livre, o culto do corpo. Certos espetáculos foram autênticos happenings consagran- 
do intelectuais, artistas, hippies. Alguns coreógrafos declararam-se a favor do consumo de drogas para aguçar a inspiração e a percepção (p. 161).

Estes diversos movimentos sociais, políticos e artísticos multiplicavam-se a todo instante, sendo interrompidos e novamente inaugurados de diferentes maneiras. Nas artes, isso ocorria à medida que os artistas experimentavam uma liberdade para criar que foi vivenciada pelas frentes precursoras dos movimentos críticos da sociedade, que geraram não uma única e grande mudança global, mas múltiplas transformações nas diferentes tramas das experimentações possíveis.

Nos Estados Unidos, vários espaços como pequenos teatros de aluguel barato, salas de associação de bairro, pátios de escolas e igrejas, museus, praças, estádios, praias, foram palcos de danças de espírito libertário, que tentavam criar outras formas de se manifestar artisticamente. Foi no auditório da igreja protestante Judson Memorial, no Greenwich Village, em Nova York, que muitos grupos e coreógrafos experimentaram uma série de trabalhos inusitados para a época. Alguns que por ali estiveram foram: Merce Cunningham, Twyla Tharp, Trisha Brown, David Gordon, Jennifer Muller, Steve Paxton, Douglas Dunn, Meredith Monk, Yvonne Rainer, Elizabeth Keen, Simone Forti, James Waring, Rudy Perez, Lucinda Childs, Karole Armitage. Teve de tudo, inclusive uma antidança ou não-dança liderada por Deborah Hay, que usava "artistas instantâneos" ou pessoas não-iniciadas, que não necessitavam de uma técnica para dançar. Na dança moderna "made in USA", esteve presente a dança aleatória, que normalmente não era executada no palco, mas no mesmo nível do chão e em meio ao público, em lugares como galerias de teatro, universidades, etc., numa tentativa de se colocar no mesmo plano de quem passava junto aos bailarinos, sem diferenciar uns dos outros. De acordo com Paul Bourcier (2001), a representante mais característica desta "nouvelle danse" foi Twyla Tharp, junto com Merce Cunningham, que buscava "composições formadas por seqüências muito elaboradas, mas que podem se sobrepor umas às outras, suceder-se em encadeamentos não obrigatórios" (p. 286). A "post modern", escola americana mais jovem, também era guiada pelo acaso, sendo priorizados os elementos brutos do movimento como girar, no lugar ou não, andar, correr, saltar em eixos repetitivos. Era a improvisação e a eventualidade que ditavam as regras, se é que se pode dizer que havia regras. Conforme Bourcier (2001),

para estes inovadores, trata-se de provocar nos executantes estados psicossomáticos - que podem atingir o espectador - que os arranque às noções restritivas da vida cotidiana. Isto implica naturalmente a participação voluntária do público a seu condicionamento mental. É o retorno à dança bruta. Esta tendência pode ser encontrada, mais ou menos marcada, em todos os dançarinos americanos, de qualquer formação. Todos procuram, sem saber designá-lo, o estado dionisíaco. Assim, o círculo se fecha e a dança volta a seu papel primitivo de transe sagrado. (p. 287)

Espetáculos multimídia faziam furor. Bailarinos com macacões esportivos dançando sem música, intérpretes literalmente subindo pelas paredes, como, por exemplo, a peça Walking on the Wall, de Trisha Brown. A mistura de bailarinos com esqueletos de animais, cactos, espantalhos, como quadros vivos inspirados em pintores como Geórgia O'Keeffe, em outra obra de Trisha Brown dançada na Sonnabend Gallery de Nova York. Conteúdos eróticos com pinceladas sadomasoquistas misturando o clássico com o punk. Simples movimentos como caminhar, sentar, levantar, deitar, que, executados em conjunto, ressaltavam as diferenças entre cada executante. Espetáculos que procuravam focalizar uma visão poética da ciência, salientando estágios do pensamento que fluem entre contemplação do cosmo e jogos corporais. E, ainda, obras coreográficas usando óculos especiais para o emprego de laser, gerando efeitos visuais como se fosse um filme de ficção científica.

Nessa multiplicidade, por mais de dez anos a vanguarda da dança nos Estados Unidos foi comandada pelo movimento da Judson Memorial, que, de acordo com Portinari (1989), entre

incontáveis propostas e resultados desiguais, alguns se tornaram menos radicais com o correr do tempo e sucesso conquistado, outros acharam mais cômodo aderir ao establishment a fim de obter subvenções para seus grupos, havendo igualmente aqueles que desapareceram sem deixar rastros (p. 161).

A dança pós-moderna norte-americana foi se tornando técnica e especializada, de acordo com Fernandes (2002), exigindo que se fizesse uma maior reflexão a respeito das relações, até então dicotômicas, entre a especialização e a abrangência artística, a técnica e a improvisação.

Nesse sentido, a dança contemporânea teve uma série de movimentos que se bifurcavam, ora desaparecendo, ora reaparecendo, mas, de qualquer maneira, gerando diferentes caminhos que se institucionalizavam em territórios mais fixos e também se desinstitucionalizavam ou se desterritorializavam, transformando-se numa heterogeneidade característica desse período de efervescência social. Isto, de alguma maneira, não foi somente uma característica no processo da dança, mas das artes em geral. Enquanto alguns grupos surgiam, bailarinos despontavam como coreógrafos, vinculando-se a uma nova formação, que estava disposta a trabalhar com a proposta que de alguma maneira procurava se diferenciar, movimentando o cenário híbrido e variado da dança contemporânea. 
A dança contemporânea foi se fazendo num processo que provocou o desmantelamento das formas, desterritorializações, uma capacidade de fazer agitar o novo, de gerar uma movimentação desconhecida. Segundo Launay e Ginot (2003),

se ainda pode-se ver a dança contemporânea como arte ou prática minoritária, ela também tem a sorte de ser, hoje, ao contrário do que seria uma prática de elite, o lugar de um pensamento consoante com as políticas de minorias que tentam fazer arte, e política, de modo diferente. Pela proliferação de suas práticas artísticas e de seus grupos de reflexão, ela não se manteve alheia à emergência de diversos movimentos sociais em todas as áreas da vida política, que resolveram opinar tanto sobre assuntos que lhes dizem respeito quanto sobre assuntos alheios (desde as associações ligadas à luta anti-mundialização, até os ecologistas radicais, ou mesmo a luta contra os transgênicos, a do ativismo feminista americano, ou ainda os grupos de ação contra a AIDS).

Mas ao que propriamente a dança contemporânea voltava-se contra? Essa dança se construiu, por todos os seus meios, na tentativa de elaborar uma crítica ao período vigente. Sua intenção, com maior ou menor consciência, era ir contra os padrões ideais estabelecidos na sociedade para o controle dos modos de viver dos homens e mulheres que queriam buscar suas próprias possibilidades de vida e que, muitas vezes, eram impedidos. A dança contemporânea queria ir contra a captura da vida, para resistir aos moldes universais que forçosamente eram criados para ser incorporados e para que a vida, digamos assim, fosse ditada fora da singularidade e do desejo.

A definição da dança contemporânea constitui-se em grande discussão, uma questão central para o domínio artístico; por isso nos propusemos a conhecê-la um pouco mais. A dança contemporânea não deixou de ser, de certa forma, um território onde vale tudo, como passos e movimentações das mais diferentes técnicas avaliadas por especialistas de toda ordem. Ainda há confusão em torno do que seja "esta tal de dança contemporânea", conforme Airton Tomazzoni (2005) ressalta como título do seu artigo. Para esse pesquisador e coreógrafo, "a dança contemporânea evidencia que escolhas estéticas revelam posturas éticas. Numa época de tantas barbáries impostas ao corpo, é preciso recuperar esta ética quando se escolhe fazer arte com o corpo - seja o seu, seja (principalmente) o dos outros". Para o autor, quatro fatos auxiliam a identificar a dança contemporânea ou, ao menos, a diferenciá-la do que ela não é. O primeiro é que a dança contemporânea é um jeito de pensar a dança, em que cada projeto coreográfico tem que forjar seu suporte técnico e fazer escolhas coerentes. Sendo assim, ela não é somente uma escola ou um tipo de aula. O segundo fato é que não há modelo ou padrão de corpo ou de mo- vimento e, por isso, na dança contemporânea pode-se reconhecer a diversidade e estabelecer o diálogo com múltiplos estilos, linguagens e técnicas de treinamento. Não há corpos que são eleitos como os melhores para essa técnica. Todo corpo é instrumento dessa dança. Já o terceiro fato constitui que a dança contemporânea reafirma a especificidade da arte da dança, ou seja, dança não é teatro, nem cinema, nem literatura, nem música, mesmo se enriquecendo muito com a contribuição destas artes. Mas dança é dança. $\mathrm{O}$ corpo em movimento estabelece sua própria dramaturgia, sua musicalidade, suas histórias, não precisando de mensagens ou mesmo de trilha sonora. O quarto e último fato compreendem o que proclamou Yvone Rainer quando a dança pós-moderna norte-americana abalava o establishment: "the mind is a muscle". Neste sentido, Tomazzoni afirma que o pensamento se faz no corpo e o corpo que dança se faz pensamento. Da mesma forma que Helena Katz (2005) aponta no prefácio do seu livro, "quando se entende a dança como um pensamento do corpo, este é o primeiro ganho: consegue-se diferenciá-la de todas as outras construções que um corpo faz com o movimento" (pp. 2-3).

A dança contemporânea conta com um período fértil da sua história de revoluções na época produtiva de movimentação social das décadas de 60 e 70 , em que se foram criando diversas linhas, que ganharam vários nomes, gerando muitas rupturas e também aproximações ou reaproximações dentro do próprio movimento da dança contemporânea. Na tentativa de evidenciar a multiplicidade gerada naquele momento fecundo, muitos nomes foram dados às diferentes correntes que ali surgiam ou que se configuravam então, de outras maneiras, tais como: dança moderna, nova dança, dança pós-moderna, espaçodança, dança-teatro etc. De qualquer maneira, essas distintas linhas da dança contemporânea surgiam como contestação ao rigor e às convenções do balé. Para as pesquisadoras de dança Aline Hass e Ângela Garcia (2003), a dança moderna surge

como necessidade de ser uma arte que promovesse e provocasse a liberdade e a exploração total do corpo a partir de temas abstratos ou concretos; com o despertar do homem para sua própria natureza, diversificando novas técnicas corporais e linhas coreográficas que iam ao encontro das necessidades de expressar acontecimentos de sua época, seus próprios sentimentos e não apenas de personagens fictícios; é a dança da libertação do corpo e de seus movimentos; é a dança que retrata todas as experiências vitais da sociedade e dos seres humanos, em que, mais uma vez, esses estão engajados e conscientes no mundo em que vivem (p. 101).

Para fins deste estudo, considera-se que a dança contemporânea não é somente o nome de todas as formas de danças existentes hoje (a dança no ou do contemporâ- 
neo), mas principalmente, nos objetivos que aqui cabem, é uma das suas modalidades que podemos também chamar de dança pós-moderna. Estas definições, ou melhor, estes nomes, ainda carecem de maior pesquisa e esclarecimentos, pois suas conceituações não estão suficientemente claras na bibliografia referente ao assunto. Talvez isto se deva ao fato do que Lia Robatto (1994) salienta na sua própria concepção de dança contemporânea:

as danças contemporâneas, participantes que são de um processo em constante renovação, não podem ser amarradas em conceitos estáticos de uma estética com estilo formal, passos e posições corporais determinados. Cada símbolo gestual ou movimento puro que surge é criado para apenas aquela determinada obra coreográfica e, pelo fato de ser único e original, terá, fatalmente, uma denominação inventada, de uso restrito ao trabalho em processo. Um seu eventual reaparecimento em outras circunstâncias, conforme o seu novo significado, poderá vir a ter até mesmo uma denominação diversa (pp. 25-26).

Fala-se então, da dança contemporânea não como um bloco único e homogêneo, mas como movimento que faz bifurcar diferentes linhas que evidenciam a multiplicidade dos modos de dançar durante o último milênio. De maneira geral, pretende-se tomar a amplitude dos movimentos da dança contemporânea, que marcaram cada vez mais seu espaço no social, demandando a possibilidade de adotar o gesto como uma ferramenta expressiva do corpo e para o corpo. Discute-se, aqui, uma dança que se propõe a novas criações, que são próprias de cada contexto e são, portanto, singulares e minoritárias, funcionando na lógica da invenção, da experimentação, na criação de elementos estéticos e expressivos para dar conta do movimento finitoilimitado da vida.

De forma análoga a essas maneiras singulares da expansão da dança contemporânea, o conceito está para a filosofia nos movimentos do pensamento de Gilles Deleuze e Felix Guattari (1992). Para fazer filosofia, de acordo com os autores, é necessário criar conceitos, ou seja, "toda criação é singular, e o conceito como criação propriamente filosófica é sempre uma singularidade" (p. 15). Conceitos que remetem a outros conceitos, ele "é uma heterogênese, isto é, uma ordenação de seus componentes por zonas de vizinhança... uma intensão presente em todos os traços que o compõem" (p. 32). São intensidades em estado de sobrevôo, que se assemelham ao procedimento do gesto e da coreografia quando estes se configuram numa possibilidade minoritária de atingir a criação e a expressão singular.

Nas palavras de Hass e Garcia (2003),

a dança contemporânea, no aspecto coreográfico, pode ser traduzida como dança que não se funde em regras, passos determinados, existentes, e técnicas pré-estabelecidas ou fixas, embora possa ser influ- enciada por determinados princípios; é uma dança que se cria e se elabora a partir de uma exploração de movimentos, gerada por uma enorme capacidade criativa, cujo objetivo é sempre a descoberta do elemento novo, estético e condutor do que deseja exprimir, expressar (p. 104).

Podemos entender a dança contemporânea de que se fala aqui, não como qualquer dança contemporânea, mas a que cria o gesto minoritário, ou seja, que faz de si uma dança menor. Por minoritário entende-se a criação ou o devir potencial que desvia do modelo, qualquer que seja seu número, conforme Deleuze e Guattari (1995). É uma variação contínua, que busca sempre a fuga, mas não a morte. Ao contrário do majoritário que domina e é uma constante do Universal, que se pode dizer que gerencia "Ninguém", o minoritário é o devir de "todo o mundo", que dá passagem a componentes novos, sendo estrangeiro na sua própria língua e compreendendo uma capacidade muito maior de expressar os movimentos da criação.

Seria como gaguejar na própria língua, inventar uma língua menor dentro da língua maior. Deleuze e Guattari (1995) nos dizem: "servir-se da língua menor para por em fuga a língua maior” (p. 51), não fazendo desta língua menor um dialeto ou novos guetos e regionalismos, pois não é assim que nos tornamos revolucionários, inventivos, mas "é utilizando muitos elementos de minoria, conectando-os, conjugando-os, que inventamos um devir específico autônomo, imprevisto" (p. 53).

É nessa provisoriedade da dança contemporânea que se pode ter uma contribuição para pensar a experiência subjetiva contemporânea, a sua relação com o corpo e com a vida possível de ser vivida no presente. Pensar uma dança menor exige ressaltar as operações de um modo de subjetivação que trabalha com a invenção a partir da imanência e da experimentação, que rompe com o platônico dualismo de gesto e corpo, emergindo um processo de risco que tenta incessantemente fazer da coreografia um procedimento, um caminho para conseguir se expressar, fazendo tudo para que o corpo possa se expressar e expresse algo do seu impensado e do seu amórfico.

O corpo desta dança menor não é nunca pronto e acabado, mas permite dar passagem ao potencial incorporal que contém e pode possibilitar o aumento das intensidades do campo sensível. Criar esse corpo potencial é suportar viver na liquidez das formas, deslizar nos fluxos, deixar rastros, inventando movimentos na dança como prática de fabricação do outramento.

Esse é o movimento de diferenciação da vida, gerador da subjetividade interessante de ser produzida. $\mathrm{O}$ leve e o pesado, conforme já salientado no início deste artigo, são elementos de um mesmo paradoxo que compreende a experiência contemporânea. Os atributos como leveza, agilidade, velocidade, geram o peso que podemos entender como a angústia sentida pelos viven- 
tes, e a leveza que conseguimos apreender como a constante desestabilização da plasticidade do tempo atual. A vida, portanto, compreende esses dois elementos, que geram o paradoxo e se constituem no movimento de diferenciação que a faz acontecer.

Assim também o gesto menor contém o leve e o pesado, imanentes na vibração da dança para que ela possa ocorrer. Retomando a música: ... "pesar do mundo... onde alivia... onde me pesa... durante a queda..." e, ain$\mathrm{da}, . .$. "somente um ritmo... peso e balanço"... Em suma, o gesto menor e o movimento de diferenciação que produz subjetividade e inventa vida compreendem o paradoxo contemporâneo da leveza e do peso.

Fala-se aqui de uma perspectiva que se insere na ordem de uma dança menor, uma dança que gagueja, que faz tropeçar seu movimento, que não faz da queda um erro. Faz da queda, do tropeço uma dança, fugindo de uma forma idealizada e homogênea de dançar. Constrói um modo de dançar através de uma política do tropeço, onde é mesmo o chão que se abre num abismo, como nos terremotos subjetivos causados pelos choques cotidianos da contemporaneidade. Assim se diz "dancei!", evidenciando a instabilidade que a dança propõe. Essa dança que é menor dentro da dança maior procura ser diferente da representação do cair. Ela constitui-se em uma ontologia da queda, para que haja dança mesmo após o tropeço, sem medo de continuar, conforme idéia de Lepecki $^{2}$ (2005). Talvez no mesmo sentido da reflexão do artista que diz "por que não ser feliz na incerteza?" Por que não continuar dançando após o tropeço?

\section{Notas}

${ }^{1}$ Pociello coloca que R. Caillois denomina "ilinx" o conjunto de jogos em que nos abandonamos a um estado físico e psicológico incontrolado.

${ }^{2}$ Lepecki, A. (2005). Tropeçando a dança: para uma política do movimento. In: Conferência apresentada no I Encontro Internacional de Dança e Filosofia - O que pode a dança? Rio de Janeiro, 15 a 18 de setembro de 2005.

\section{Referências Bibliográficas}

Bauman, Z. (2001). Modernidade líquida. Rio de Janeiro: Jorge Zahar.

Bergson, H. (1964). A evolução criadora. Rio de Janeiro: Editora Delta.

Bourcier, P. (2001). História da dança no Ocidente. São Paulo: Martins Fontes.

Calvino, I. (1990). Seis propostas para o próximo milênio: lições americanas. São Paulo: Companhia das Letras.

Deleuze, G. \& Guattari, F. (1992). O que é a filosofia? Rio de Janeiro: Ed. 34.

Deleuze, G. \& Guattari, F. (1995). Mil platôs - Capitalismo e esquizofrenia (Vol. 2). Rio de Janeiro: Ed. 34.

Fernandes, C. (2002). O corpo em movimento: o sistema Laban/
Bartenieff na formação e pesquisa em artes cênicas. São Paulo: Annablume.

Haas, A. \& Garcia, Â. (2003). Ritmo e dança. Canoas, RS: ULBRA. Katz, H. (2005). Um, dois, três. A dança éo pensamento do corpo. Belo Horizonte: FID.

Launay, I. \& Ginot, I. (2003). Uma fábrica de anti-corpos? (N. Alves, Trad.). Acesso em 24 de novembro, 2005, em http:// idanca.net/lang/pt-br/2003/01/01/uma-fabrica-de-anti-corpos/

Lipovetsky, G. (1989). O império do efêmero: a moda e seu destino nas sociedades modernas. São Paulo: Companhia das Letras.

Pociello, C. (1995). Os desafios da leveza: as práticas corporais em mutação. In D. Sant'Anna (Org.), Políticas do corpo. São Paulo: Estação Liberdade.

Portinari, M. (1989). História da dança. Rio de Janeiro: Nova Fronteira.

Robatto, L. (1994). Dança em processo, a linguagem do indizivel. Salvador: Centro Editorial e Didático da UFBA.

Rolnik, S. (2001). Molda-se uma alma contemporânea: o vaziopleno de Lygia Clark. In B. Bezerra \& C. Plastino (Orgs.), Corpo, afeto e linguagem: a questão do sentido hoje. Rio de Janeiro: Rios Ambiciosos.

Simondon, G. (2003). A Gênese do indivíduo. In P. Pelbart \& R. Costa (Orgs.), O reencantamento do concreto (Cadernos de subjetividade, pp. 99-117). São Paulo: Editora Hucitec.

Tomazzoni, A. (2005). Esta tal de dança contemporânea. Revista Aplauso, 70. Acesso em 23 de novembro, 2006, em http:// w w w. a pla u s o.com.br/site/portal/ anteriores.asp?campo $=464 \&$ secao_id $=47$

Varela, F. (2003). O reencantamento do concreto. In P. Pelbart \& R. Costa (Orgs.), O reencantamento do concreto (Cadernos de subjetividade, pp. 71-86). São Paulo: Editora Hucitec.

Wisnik, J. \& Neves, P. (s.d.). Pesar do mundo. Acesso em 10 de julho, 2006, em http://www.mpbnet.com.br/musicos/ ze.miguel.wisnik/letras/pesar_do_mundo.htm

Patrícia Spindler é Psicóloga, trabalha com clínica grupal e individual e é mestre do Programa de Pós-

Graduação em Psicologia Social e Institucional da Universidade Federal do Rio Grande do Sul. Endereço para correspondência: Av. Cel. Frederico Linck, 784/46 -

Novo Hamburgo/RS.E-mail: patriciaspindler@hotmail.com

Tania Mara Galli Fonseca é Psicóloga, Professora dos Programas de Pós-Graduação em Psicologia Social e Institucional e de Informática Educativa da Universidade Federal do RGS. Endereço para correspondência: Rua Campos Salles, 262- Bairro Boa vista- Porto Alegre/RS- Cep- 90480-030 E-mail: tfonseca@via-rs.net

Dançando o pesar do mundo

Patrícia Spindler e Tania Mara Galli Fonseca

Recebido: 09/10/2007

Revisão: 29/11/2007

Aceite: $15 / 11 / 2007$ 